\title{
(AN INVESTIGATION INTO WHETHER) THE AD-HOC NATURE OF PROJECT ENVIRONMENTS INCREASES THE NEED FOR STRONG PROJECT LEADERS
}

\author{
Lambi C. Hubbard, PMP, Argosy University, lhubbar2@chi.stu.argosy.edu
}

\begin{abstract}
Project environments are ad-hoc, unique undertakings that experience more change than operational environments. There is an immediate change to the environment when a project is initiated. A project manager's ultimate task is to successfully change the environment. These managers of change require vital leadership skills to ensure progress and prevent chaos. Therefore, project environments require strong leaders. The overriding concept is that the field of project management needs to place greater emphasis on leadership. Having its roots in the engineering and mathematical sciences, project management tends to emphasize management and prescriptive processes, rather than informing practitioners on how to inspire people to accomplish goals by providing them clear purpose, direction, and motivation.
\end{abstract}

Keywords: Project Management, Leadership, Project Leadership

\section{INTRODUCTION}

By definition, projects are unique undertakings that are designed to achieve a unique, product, service, or result. By nature, project environments experience more change and volatility than traditional organizations. With such change moving at a high velocity, the ability to resolve conflicts requires an assumed role. According to Cadwell and Karri (2005) in an evaluation of agency, stakeholder and stewardship theories, a manager's covenantal duties are multi-threaded. In project environments, project managers are to ensure that maximum short-term wealth for the Principle is achieved. They must also be a balancer of demands, an advocate of collective interest, and an integrator of shared interests (2005). If this state of mind is not utilized by a multidimensional persona, there may be an inability to resolve conflict when it arises. In a project environment, a project manager must work from a toolbox to exploit these theories. In an operational environment, line managers may only be expected to employ one theory at a time.

In order to collaborate effectively, team members require a shared knowledgebase. Without a shared context, the ability to communicate is limited. On the contrary, teams that do not have diverse knowledge bases are not challenged to learn from their temporary environment. It is critical for the project manager to set the stage for knowledge sharing and creation during every project event.

With these elements, project environments require strong leaders. Without strong leadership, project teams may not develop the shared context required for collaboration in sufficient time. Most importantly, successfully execute projects for the organization. Management literature already indicates a correlation between leadership and project outcomes by stating leadership is required in order to ensure progress and prevent chaos (Mintzberg, 1998). Interestingly, project management could be considered 'managed chaos'.

\section{LITERATURE REVIEW}

Although leadership and management are oftentimes used synonymously, these terms have different meanings and purposes. As argued by Bedell, Hunter, Angie, and Vert (2006), leadership is a compilation of skills that promulgates positive performance within others. Skills suggestive of, the ability to inspire, developing a bridge of communication amongst stakeholders, and creating an environment of trust are foundation layers of leadership. Leaders who own these skills motivate participants to perform in measures that were not initially imagined. In addition, these skills motivate participants to travel in the path of the unknown with confidence. As an ongoing measure, with strong leadership, participants protect their leader's vision by delivering their best version of labor.

Leaders exist in three categories: Charismatic, ideological and pragmatic. Charismatic leaders use shared experiences and an emotional, future-oriented vision to inspire followers. Ideological leaders concentrate on shared pasts and values for a just society to engage followers. Pragmatic leaders are functional problem solvers looking for a solution (Bedell, Hunter, Angie, \& Vert, 2006). Overall, leaders seek to prioritize actions. They utilize appreciative inquiry to focus on strengths, rather than weaknesses. 
Situational leadership has been the default leadership style adopted by project managers. Traditionally, line managers use situational leadership to resolve conflicts. When line managers employ situational leadership, direction, coaching, supporting or delegating approaches are used. The approach is then coupled with an evaluation of the individual(s) competence level. This technique ensures that each situation is viewed as a unique event.

Although successful in line management, situational leadership is not effective in project environments. Project environments are complex organisms. These organisms require input from various perspectives such as: core team members, functional and senior management, and customers. To resolve conflict in a project environment, project managers require a great deal of trust and domain knowledge to balance these perspectives for proper decision-making.

In addition to conflict resolution, preventing project failure requires proper project leadership. According to May (1998), project failure is related to the inability to coordinate project resources and evoke communication among stakeholders. McFarlan (1982) suggests that project failure occurs due to the lack of understanding the new system. This misinterpretation of the new system falls heavily on the project manager. It is the project manager's responsibility to ensure that there is effective communication throughout a project, from conception to implementation. In a study conducted by Kappelman, McKeeman, and Zhang (2006) the top reasons for project failure fall into two risk categories: People-Related Risks and ProcessRelated Risks. People-related risks consists of, lack of top management support, weak project manager, no stakeholder involvement, weak commitment of project team, team members lack requisite knowledge, subject matter experts overscheduled, are the responsibility of the project manager. Processrelated risks consists of; lack of documented requirements and/or success criteria, no change control process, ineffective schedule planning and or management, communication breakdown among stakeholders, resources assigned to a higher priority project, and no business case for the project are also responsibilities of the project manager. In initial stages in a project, however, project managers must have an inclination when a project will not be successful. Kiel and Montealegre (2001), advises that an emergency system for project termination be created in organizations to prevent failure.

During project execution, the project manager is responsible for promoting a shared culture and enhancing team maturity. Nonaka and Toyama's "Ba" support a shared culture (Nonaka, 1998). Shared culture and context promotes the integration of tacit knowledge. The integration of tacit knowledge promotes successful project outcomes by enabling knowledge creation. Since projects are unique endeavors, knowledge creation and/or integration are necessary conditions for project success. It is imperative that project managers own the ability to integrate specialists from crossfunctional groups. This skill not only promotes project efficiency, however, it will also increase the maturity level of the organization. As a result of this unique event, knowledge stocks, (documentation of new processes and procedures), in addition to, knowledge flows, (increasing interaction among functional groups), are the responsibilities of the project manager.

In a comparison of Mintzberg's 1973 publication, “The Nature of Managerial Work” (2005), Tengbald revealed that today's managers, in comparison to managers' decades ago, work load and responsibilities has increased substantially. Managers attend more meetings with multiple participants at a given time. They're also responsible for giving information and direction like never before. This increase is a result of the expectation to deliver to markets faster. For many organizations, getting to the market before their competitors is a competitive advantage strategy. With this, the increasing competitiveness in the marketplace increases the need for project managers to have the ability to execute successful projects.

\section{DISCUSSION}

An increased emphasis on leadership in the domain of project management is necessary for many reasons. There is an increased complexity of markets served which results in a greater complexity of project teams. The increased need for strong project leaders is motivated by the increased complexity of project teams (Jones, 2004). A primary function of project managers is to integrate the knowledge of specialists.

Project environments are become more complex due to the growth range of competitors that any given organizational would encounter for the fight for market share. It is during these times that new product and growth opportunity projects are planned and executed to not only competing, but to conduct business as usual. With this new type of organic organization, there is a dire need to position project managers in pivot arenas just to maintain. These 
managers must have strong leadership skills to take the organization to the main stream.

\section{CONCLUSION}

Recommendations for the project management work group are to conduct skills inventory focusing on the leadership of project managers within the organization. This exercise will reveal natural leadership styles while, simultaneously, exposing individual leadership strengths and weaknesses. After conducting the leadership inventory, is imperative that research is conducted to identify leadership training that is in alignment with the project manager work group's needs. In addition, it's vital that project managers attending training conduct after action reviews with management to evaluate effectiveness. Over and above evaluation training, an implementation plan must be created to incorporate new skills (Mintzberg, 1999). Within the implementation plan, it's essential that monitoring procedures are included to evaluate the project manager's leadership skills for a specific project.

For the project leadership initiative to be successful, management is required to employ the system's approach to ensure the social system of the organization is considered. To maintain momentum, small wins should be planned though setting program milestones (Kotter, 1995) along with public communication outlying progress. To reinforce change, evaluation measuring satisfaction levels of management, project team members and project managers should also be conducted.

By participating in an organizational shift of nature, it might be perceived that there is a deficiency in performance. The timeline of this culture change or evolution of project managers could possibly take years to become reality, however, the benefits of having more successful projects transposed from the hands of project leaders could potentially earn great profits for organizations.

\section{REFERENCES}

1. Bedell, K., Hunter, S., Angie, A., and Vert, A. (2006). A Historical Examination of Machiavellianism and a New Taxonomy of Leadership. Journal of Leadership and Organizational Studies, 12(4), 50-72.

2. Caldwell, C., and Karri, R., (2005). Organizational Governance and Ethical Systems: A Covenantal Approach to Building Trust. Journal of Business Ethics, 58, 249-259.
3. Jones, C. (2004). Software Project Management Practices: Failure Versus Success. CrossTalk: The Journal of Defense Software Engineering, October, 5-9.

4. Kappelman, McKeeman, and Zhang (2006). Early Warning Signs of IT Project Failure: The Dominate Dozen. Journal of information Systems Management Fall 31 - 36.

5. Keil, M. and Montealegre, R. (2001). Cutting Your Losses: Extricating Your Organization When a Big Project Goes Awry, MIT Sloan Management Review, 41 (3) 55-68.

6. Kotter, J., (1995). Leading Change: Why Transformation Efforts Fail. Harvard Business Review. March -April 59-67.

7. May, L.J. (1998). Major Causes of Software Project Failures, CrossTalk: The Journal of Defense Software Engineering, July, 9-12.

8. McFarlan, W. (1982). Portfolio Approach to Information Systems. Journal of Systems Management, January, 12-19.

9. Mintzberg, H. (1998). Covert Leadership: Notes on Managing Professionals. Harvard Business Review, 76 (6), 140-147.

10. Mintzberg, H., \& Lampel, J. (1999) Reflecting on the Strategy Process. MIT Sloan Management Review,40(3), 21-30.

11. Nonaka, I., Konno, N., (1998). The concept of "Ba": Building a Foundation for knowledge Creation. California Management Review 40(3) 40-54.

12. Tengbald, S., (2006). Is there a 'New Managerial Work'? A Comparison with Henry Mintzberg's Classic Study 30 Years Later*. Journal of Management Studies 43(7), 1437-1461. 